\title{
THE RESIDUAL LATERAL EARTH PRESSURE ON RETAINING WALL DUE TO VIBRATORY ROLLERS
}

\author{
Moamen E. Abd El Raouf \\ Civil Engineering Department, Faculty of Engineering, Al- Azhar University, Egypt
}

\begin{abstract}
Compaction of backfill behind a retaining wall is normally affected by the compactors. The compaction plant can be represented approximately by a surcharge load equal to the weight of the roller. If a vibratory roller is employed, the centrifugal force due to the vibrating mechanism should be added to the static weight. After compaction, the lateral stress does not revert to the basic value $\left(\mathrm{k}_{\mathrm{a}} \gamma \mathrm{z}\right)$. At a certain depth, the residual lateral pressure may be high enough to cause passive failure in the soil behind the retaining wall. The present paper analyses the effect of compaction of the backfill behind the retaining walls. The values of the residual lateral earth pressure induced by common compacting equipment the most parts of the world especially in Egypt are calculated by the classical methods (the method of Canadian code of Practice). The study compares the method of Canadian Practice results and the results of the analysis using the finite element to enhance the method of calculation the lateral earth pressure due to compaction.
\end{abstract}

\section{KEYWORDS: Residual Earth Pressure, Retaining Wall, Soil compaction, Vibratory Rollers1}

\section{INTRODUCTION}

The main purpose of retaining wall is to retain soil, so soil lateral earth pressure is a major factor in the design of retaining wall. There are various types of loads and forces acting on retaining wall, like lateral earth pressure, surcharge loads, line loads, wind on projecting stem, seismic forces and the effects of backfill compaction. Coarse grained soils usually used as backfill behind retaining walls. The layers of backfill soil are compacted by various compactors. Compaction of fill behind retaining wall in lavers by rollers, vibrating plates, or rammers induces additional lateral earth pressures that vary in magnitude and distribution from those predicted using the classical earth pressure theories of Coulomb (1776) and Rankine (1857). Compaction of backfill behind a retaining wall is normally affected by rolling. The compaction plant can be represented approximately by a line load equal to the weight of the roller. If a vibratory roller is employed, the centrifugal force due to the vibrating mechanism should be added to the static weight [1]. The additional earth pressure on retaining wall due to compaction depends on the width of the backfill zone, type of backfill, weight and the type of compaction equipment used [2].The effects of compaction backfill are traditionally neglected in the calculations of forces act on retaining walls in Egypt and many countries. As shown in figure (1) after compaction, the lateral stress does not revert to the basic value $\left(\mathrm{k}_{\mathrm{a}} \gamma \mathrm{z}\right)$. At a certain depth, the residual lateral pressure may be high enough to cause passive failure in the soil behind the retaining wall; also, the lateral earth pressure measured near the top of the wall was almost identical to the passive earth pressure estimated by Rankine theory. If the cyclic compacting stress applied on the surface of the backfill exceeded the ultimate bearing capacity of the foundation soil, a shear failure zone would develop in the uppermost 
layer of soil [3]. The effect of compaction on the lateral earth pressure behind retaining walls can be calculated by various methods.
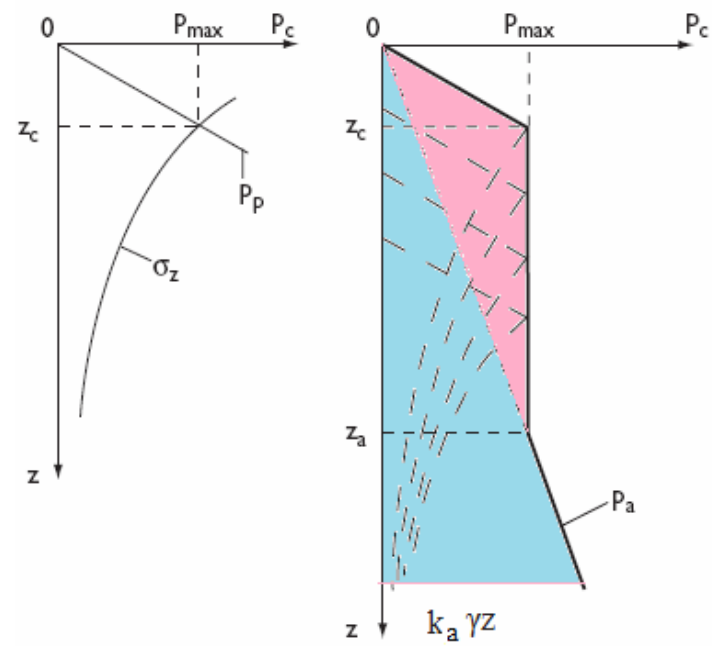

Figure (1) Compaction-induced pressure (R.F.Craig, 2004)

The present paper analyses the effect of compaction of the backfill behind the retaining walls. The values of lateral earth pressure induced by common compacting equipment the most parts of the world especially in Egypt are calculated. The study compares the method of Canadian code of practice results and the results of the analysis using the finite element to enhance the method of calculation the lateral earth pressure due to compaction. The study aims to give recommendations to reduce the effect of compaction process on retaining wall to avoid excessive additional earth pressures, which may lead to unacceptable movements.

\section{2-Estimate the Earth Pressure Due to Compaction}

The effect of compaction on the lateral earth pressure behind retaining walls has been studied by several methods as follows:

\section{2-1 Manual Calculations}

Methods those are simple enough for hand calculations have been developed by several researchers [4-5-6-7-8-9]. Although these methods are simpler, but one or two hours of calculation are required for analysis of a single case. In addition, these methods lack accuracies in some cases [10]. Also, charts were developed by Duncan and Seed (1986) to estimate the earth pressures due to compaction by Rollers, Vibratory plates, and Rammers. The charts were developed to make it possible to estimate compaction-induced earth pressures quickly and reliably. For conditions other than those on which the charts are based, adjustments are made using the multiplier factors [10-11].

\section{2-2 Elasticity Theory}

Theory of elasticity can be used to calculate the lateral earth pressure behind the retaining wall from surcharge loadings, such as point load, line loading, and strip loading, so, the earth pressure behind retaining wall due to compaction can be calculated according to elasticity theory by using Boussinesq's equation modified by experiments and site investigation as shown in figure (2). 

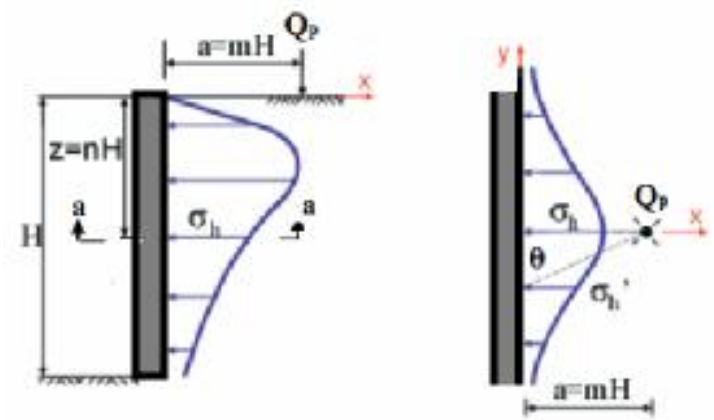

Section a-a

Figure (2) Lateral earth Pressure from pint load $Q_{p}$

For the retaining wall with height $(\mathrm{H})$, the lateral earth pressure due to compaction $\left(\sigma_{\mathrm{h}}\right)$ at a depth (z) can be calculated from the following formula [12, 13].

$$
\begin{gathered}
\sigma_{h}=\frac{0.28\left(\frac{z}{H}\right)^{2}}{\left\{0.16+\left(\frac{z}{H}\right)^{2}\right\}^{3}} \frac{Q_{p}}{H^{2}} \quad \text { for } \frac{a}{H} \leq 0.4 \\
\sigma_{h}=\frac{1.77\left(\frac{a}{H}\right)^{2}\left(\frac{z}{H}\right)^{2}}{\left\{\left(\frac{a}{H}\right)^{2}\left(\frac{z}{H}\right)^{2}\right\}^{3}} \frac{Q_{p}}{H^{2}} \quad \text { for } \frac{a}{H}>0.4 \\
\sigma_{h}^{\prime}=\sigma_{h} \cos ^{2}(1.1 \theta)
\end{gathered}
$$

Where: $\mathrm{Q}_{\mathrm{p}}=\mathrm{P}_{\mathrm{s}}+\mathrm{P}_{\mathrm{c}=}$ the static weight of the roller + centrifugal force

\section{2-3 The Canadian Code of Practice}

In Canadian code of practice [12], it is assumed that the compaction of backfill behind the wall produces additional lateral earth pressure on the wall. Figure (3) illustrates the distribution and magnitude of earth pressure due to compaction as recommended by the Canadian Geotechnical Society [8].

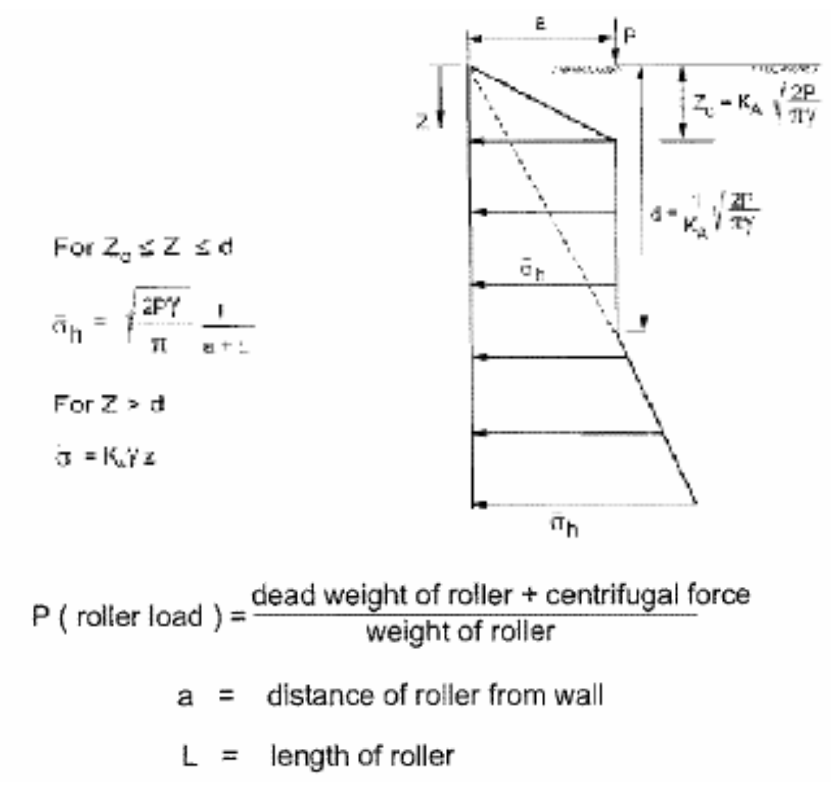

Figure (3) Horizontal pressure on walls from compaction effort . 


\section{3- VIBRATORY COMPACTION}

Vibratory compaction is one of the most economical methods for compacting different types of soils. Vibratory compactors are generally divided into two classes; rollers and plates. Rollers impart vibration to the ground through a steel drum (single or double) Plates vibrations affect directly to the soil through skids which vibrated by eccentric devices driven electrically or mechanically. Various types of compaction equipment (vibratory rollers and plates) are used for compacting the backfill behind retaining structures in Egypt and most parts of the world. By Survey and research, it was found that the most common vibratory rollers in are produced by companies: Caterpillar, Dynapac, Bomag, and Ingersoll Rand. In this search, the latest models of these products were studied [14-15-16]. A data about compaction equipment was collected which include:

1) The manufacturers and the model.

2) The static weight $\left(P_{s}\right)$ which is the weight of the vibrators portion of the machine.

3) Centrifugal force or the dynamic force $\left(\mathrm{P}_{\mathrm{c}}\right)$ which is the power from each impulse induced by the centrifugal force.

4) The dimension of the area of the vibrator contacting the soil (Roller width L).

The collected data was listed in the table (1). Figures (4) shows the most common compaction equipment in Egypt.

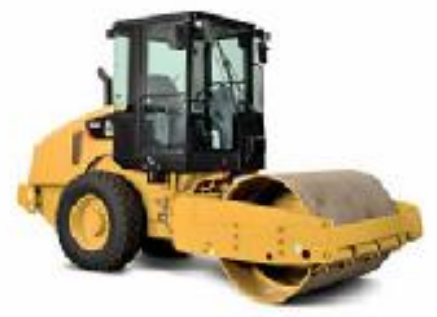

Caterpillar (Model CS44B) vibratory roller

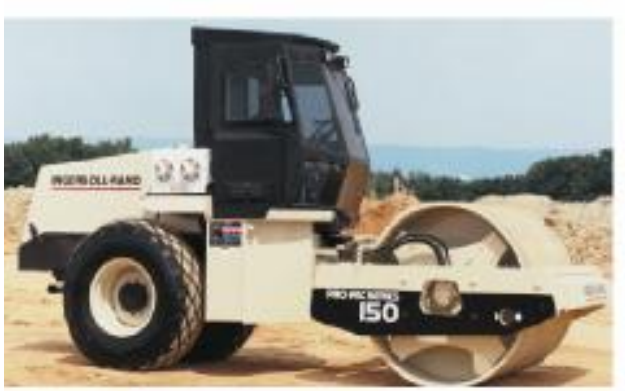

Ingersoll Rand Roller

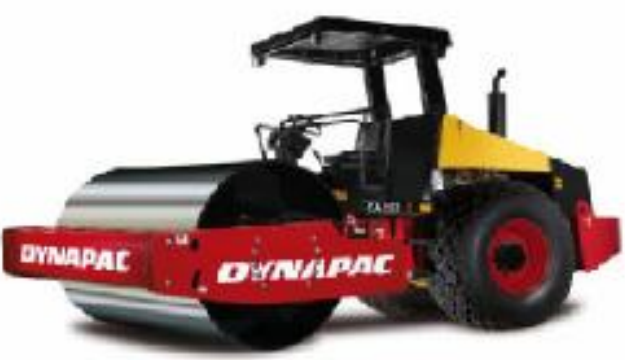

Dynapac (Model CA250) vibratory roller

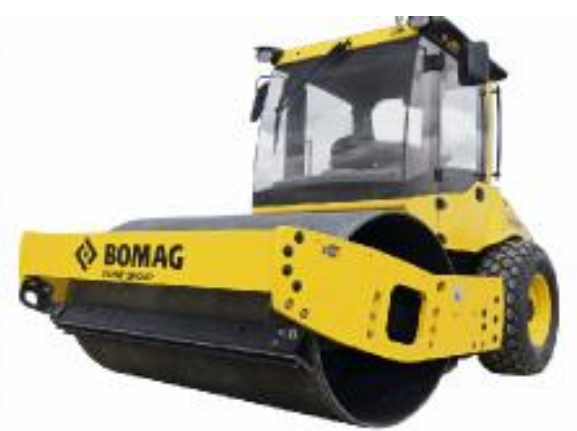

Bomas (single drum roller BW 197 DH-5) vibratory roller

Figures (4) The most common compaction equipment

Table (1) Data of the vibratory rollers with single drum

\begin{tabular}{|c|c|c|c|}
\hline Manufacturer & $\begin{array}{c}\left(\mathbf{P}_{\mathbf{S}}\right) \\
\mathbf{k N}\end{array}$ & $\left(\mathbf{P}_{\mathbf{c}}\right) \mathbf{k N}$ & $\begin{array}{c}\text { Roller } \\
\text { width }(\mathbf{L}) \mathbf{m m}\end{array}$ \\
\hline Dynapac & $13-80$ & $\mathbf{8 9 - 3 3 0}$ & $1370-2130$ \\
\hline Ingersoll Rand & $64-180$ & $135-360$ & $1675-2540$ \\
\hline Bomag & $\mathbf{5 6 - 2 6 7}$ & $\mathbf{8 0 - 3 2 8}$ & $1426-2130$ \\
\hline Caterpillar & $45-187$ & $\mathbf{6 6 . 8 - 3 3 2}$ & $1270-2134$ \\
\hline
\end{tabular}

\section{4-Calculation of Earth pressure on Retaining Wall due to Compaction}

The distribution and magnitude of earth pressure on retaining wall due to compaction are calculated according to Canadian Geotechnical Society for $\mathrm{a}=0,1,2 \ldots$ till $70 \mathrm{~m}$ as shown in 
table (2). Where $a=$ the distance of the roller from the wall. A Microsoft Excel module was done by the researcher to calculate the earth pressure due to compaction according to the Canadian Geotechnical Society as shown in figure (5). Data is inserted and extracted, into Microsoft Excel modules. These data are as follows: 1) The rammer static weight (Ps); 2) Centrifugal force (Pc); 3) Roller length (L); 4) the backfill density ( $\gamma$ had been assumed to be $\left.18 \mathrm{kN} / \mathrm{m}^{3}\right)$; 5) Distance of the roller from the wall (a).

The results had been collected and tabulated as shown in table (2)

\section{The method of Canadian Code of Practice}

For $Z c \leq \leq \leq d$ $d=\frac{1}{K_{A}} \sqrt{\frac{2 P}{\pi \gamma}}$

\begin{tabular}{|c|c|c|c|c|c|c|c|c|}
\hline$\gamma(\mathrm{kN} / \mathrm{m} 3)$ & $\mathbf{L}(\mathbf{m})$ & $a(m)$ & Ps $(k N)$ & $\operatorname{Pc}(\mathrm{kN})$ & $\mathrm{p}($ roller load $)(\mathrm{kN})$ & $L /(a+L)$ & $\sqrt{ }(2 \mathrm{p} \gamma / \pi)$ & $\sigma \mathrm{h} \mathrm{kN} / \mathrm{m} 2 / \mathrm{m}$ \\
\hline 18 & 1.676 & 0 & 20 & 144 & 8.20 & 1 & 9.70 & 9.70 \\
\hline 18 & 1.676 & 1 & 20 & 144 & 8.20 & 0.63 & 9.70 & 6.07 \\
\hline 18 & 1.676 & 2 & 20 & 144 & 8.20 & 0.46 & 9.70 & 4.42 \\
\hline 18 & 1.676 & 3 & 20 & 144 & 8.20 & 0.36 & 9.70 & 3.48 \\
\hline 18 & 1.676 & 4 & 20 & 144 & 8.20 & 0.30 & 9.70 & 2.86 \\
\hline 18 & 1.676 & 5 & 20 & 144 & 8.20 & 0.25 & 9.70 & 2.43 \\
\hline 18 & 1.676 & 6 & 20 & 144 & 8.20 & 0.22 & 9.70 & 2.12 \\
\hline 18 & 1.676 & 7 & 20 & 144 & 8.20 & 0.19 & 9.70 & 1.87 \\
\hline 18 & 1.676 & 8 & 20 & 144 & 8.20 & 0.17 & 9.70 & 1.68 \\
\hline 18 & 1.676 & 9 & 20 & 144 & 8.20 & 0.16 & 9.70 & 1.52 \\
\hline 18 & 1.676 & 10 & 20 & 144 & 8.20 & 0.14 & 9.70 & 1.39 \\
\hline 18 & 1.676 & 11 & 20 & 144 & 8.20 & 0.13 & 9.70 & 1.28 \\
\hline 18 & 1.676 & 12 & 20 & 144 & 8.20 & 0.12 & 9.70 & 1.19 \\
\hline 18 & 1.676 & 13 & 20 & 144 & 8.20 & 0.11 & 9.70 & 1.11 \\
\hline 18 & 1.676 & 13 & 20 & 144 & 8.20 & 0.11 & 9.70 & 1.11 \\
\hline 18 & 1.676 & 14 & 20 & 144 & 8.20 & 0.11 & 9.70 & 1.04 \\
\hline 18 & 1.676 & 15 & 20 & 144 & 8.20 & 0.10 & 9.70 & 0.97 \\
\hline 18 & 1.676 & 16 & 20 & 144 & 8.20 & 0.09 & 9.70 & 0.92 \\
\hline
\end{tabular}

Figure (5) The Microsoft Excel module

Table (2) Estimation Lateral earth pressure due to compaction by vibratory roller by the method of Canadian

\begin{tabular}{|c|c|c|c|c|c|c|c|}
\hline Manufacturer & Model & $\begin{array}{c}\sigma_{\mathrm{h} \mathrm{kN} / \mathrm{m}^{2}} \\
\mathbf{a}=\mathbf{0}\end{array}$ & $\begin{array}{l}\sigma_{\mathrm{h} \mathrm{kN} / \mathrm{m}^{2}} \\
\mathbf{a}=1 \mathrm{~m}\end{array}$ & $\begin{array}{l}\sigma_{\mathrm{h} \mathrm{kN} / \mathrm{m}^{2}} \\
\mathbf{a}=\mathbf{2 m}\end{array}$ & $\begin{array}{c}\sigma_{\mathrm{h} \mathrm{kN} / \mathrm{m}}{ }^{2} \\
\mathrm{a}=\mathbf{3 m}\end{array}$ & $\begin{array}{l}\sigma_{\mathrm{h} \mathrm{kN} / \mathrm{m}^{2}} \\
\mathrm{a}=\mathbf{1 0 m}\end{array}$ & $\begin{array}{l}\sigma_{\mathrm{h} \mathrm{kN} / \mathrm{m}^{2}} \\
\mathbf{a}=\mathbf{2 0 m}\end{array}$ \\
\hline Dynapac & CA1300D & 9.48 & 5.48 & 3.86 & 2.97 & 1.14 & 0.61 \\
\hline Dynapac & CA1400D & 9.7 & 6.07 & 4.42 & 3.48 & 1.39 & 0.75 \\
\hline Dynapac & CA1500D & 9.17 & 5.74 & 4.18 & 3.29 & 1.32 & 0.71 \\
\hline Dynapac & CA2500D & 11.03 & 7.5 & 5.6 & 4.58 & 1.94 & 1.06 \\
\hline Dynapac & CA3600D & 10.03 & 6.83 & 5.17 & 4.17 & 1.76 & 0.97 \\
\hline Dynapac & CA4000D & 9.33 & 6.35 & 4.81 & 3.87 & 1.64 & 0.9 \\
\hline Dynapac & CA5000D & 9.33 & 6.35 & 4.81 & 3.88 & 1.64 & 0.9 \\
\hline Dynapac & CA5500D & 9.23 & 6.28 & 4.76 & 3.83 & 1.62 & 0.89 \\
\hline Dynapac & CA6000D & 8.96 & 6.1 & 4.62 & 3.72 & 1.57 & 0.86 \\
\hline Dynapac & CA6500D & 8.66 & 5.89 & 4.47 & 3.59 & 1.52 & 0.83 \\
\hline Dynapac & CA702D & 7.67 & 5.22 & 3.95 & 3.18 & 1.35 & 0.74 \\
\hline $\begin{array}{l}\text { Ingersoll } \\
\text { Rand }\end{array}$ & $\begin{array}{l}\text { SD-70D } \\
\text { PRO-PAC }\end{array}$ & 5.98 & 7.35 & 2.73 & 2.14 & 0.86 & 0.46 \\
\hline $\begin{array}{l}\text { Ingersoll } \\
\text { Rand }\end{array}$ & $\begin{array}{l}\text { SD-70F } \\
\text { TERRA }\end{array}$ & 5.87 & 3.67 & 2.67 & 2.1 & 0.84 & 0.45 \\
\hline
\end{tabular}


THE RESIDUAL LATERAL EARTH PRESSURE ON RETAINING WALL DUE TO VIBRATORY ROLLERS

\begin{tabular}{|c|c|c|c|c|c|c|c|}
\hline & FIRMA & & & & & & \\
\hline $\begin{array}{l}\text { Ingersoll } \\
\text { Rand }\end{array}$ & SD-100D & 6.01 & 4.1 & 3.1 & 2.5 & 1.06 & 0.58 \\
\hline $\begin{array}{l}\text { Ingersoll } \\
\text { Rand }\end{array}$ & $\begin{array}{l}\text { SD-120D } \\
\text { PRO-PAC }\end{array}$ & 5.76 & 3.92 & 2.97 & 2.39 & 1.01 & 0.56 \\
\hline $\begin{array}{l}\text { Ingersoll } \\
\text { Rand }\end{array}$ & $\begin{array}{l}\text { SD-150F } \\
\text { PRO-PAC }\end{array}$ & 5.97 & 4.07 & 3.08 & 2.48 & 1.05 & 0.58 \\
\hline $\begin{array}{l}\text { Ingersoll } \\
\text { Rand }\end{array}$ & $\begin{array}{l}\text { SD-180F } \\
\text { PRO-PAC }\end{array}$ & 5.86 & 4.2 & 3.28 & 2.69 & 1.19 & 0.66 \\
\hline Bomag & BW 145 D-5 & 5.28 & 3.1 & 2.2 & 1.7 & 0.66 & 0.35 \\
\hline Bomag & BW 177 D-5 & 5.28 & 3.32 & 2.42 & 1.9 & 0.76 & 0.41 \\
\hline Bomag & $\begin{array}{l}\text { BW } 197 \text { DH- } \\
5\end{array}$ & 5.17 & 3.38 & 2.52 & 2 & 0.82 & 0.45 \\
\hline Bomag & BW 211 D-5 & 5.37 & 3.9 & 2.95 & 2.38 & 1.01 & 0.55 \\
\hline Bomag & $\begin{array}{l}\text { BW } 211 \text { D- } \\
40\end{array}$ & 5.68 & 3.87 & 2.93 & 2.36 & 1 & 0.55 \\
\hline Bomag & BW 214 D-5 & 5.61 & 3.82 & 2.9 & 2.33 & 0.99 & 0.54 \\
\hline Bomag & $\begin{array}{l}\text { BW } 216 \text { D- } \\
40\end{array}$ & 5.74 & 3.72 & 2.82 & 2.27 & 0.96 & 0.53 \\
\hline Bomag & $\begin{array}{l}\text { BW } 218 \text { D- } \\
40\end{array}$ & 5.29 & 3.6 & 2.73 & 2.2 & 0.93 & 0.51 \\
\hline Bomag & $\begin{array}{l}\text { BW } 226 \\
\text { DH-5 }\end{array}$ & 5.05 & 3.44 & 2.61 & 2.1 & 0.89 & 0.49 \\
\hline Caterpillar & CS34 & 5.36 & 3 & 2.08 & 1.59 & 0.6 & 0.32 \\
\hline Caterpillar & CS44B & 5.71 & 3.58 & 2.6 & 2.05 & 0.82 & 0.44 \\
\hline Caterpillar & CS54B & 6.07 & 4.14 & 3.13 & 2.52 & 1.07 & 0.59 \\
\hline Caterpillar & CS64B & 5.81 & 3.95 & 3 & 2.41 & 1.02 & 0.56 \\
\hline Caterpillar & CS78B & 5.64 & 3.84 & 2.91 & 2.34 & 0.99 & 0.54 \\
\hline
\end{tabular}

The relation between the compaction -induced earth pressure and the distance of the roller from the wall is explained in figure (6).

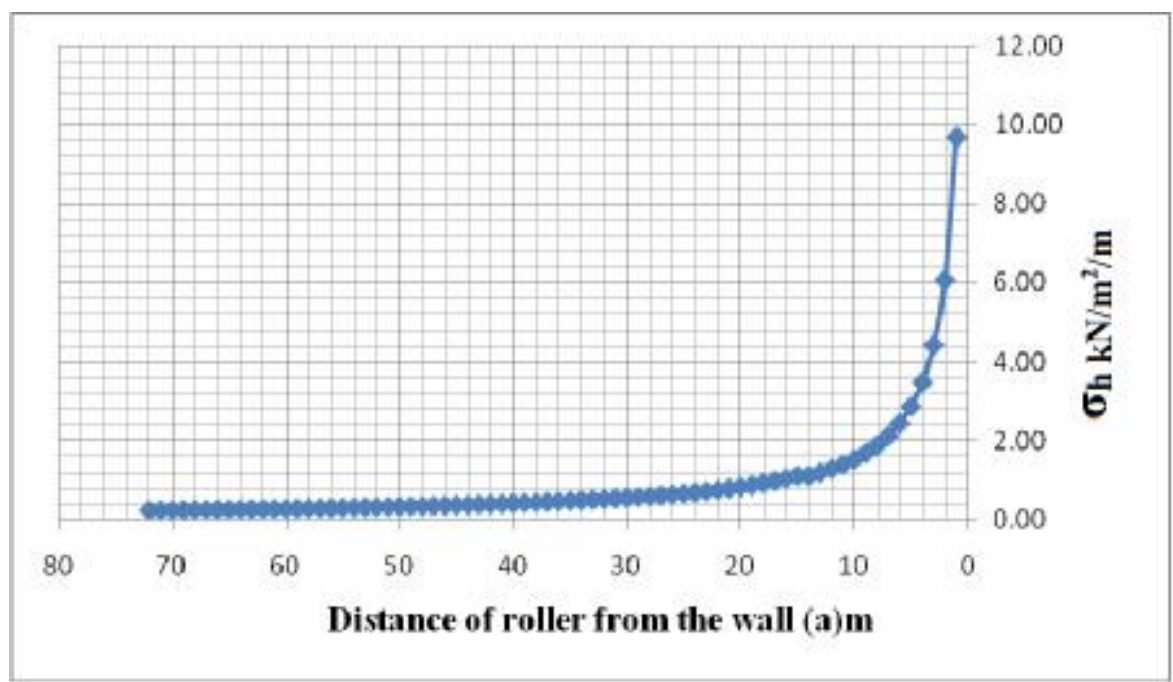

Figure (6) The relation between the earth pressure due to compaction and the distance of roller from the wall

\section{4-1 Effect of Backfill Density on Compaction-Induced Earth Pressure}

The effect of soil density on residual lateral earth pressure due to compaction has been studied 
using Canadian Practice method as shown in figure (7). Three types of backfill have $\gamma=16$ $\mathrm{kN} / \mathrm{m}^{3}, 20 \mathrm{kN} / \mathrm{m}^{3}$, and $25 \mathrm{kN} / \mathrm{m}^{3}$ was studied. The results indicate that the increase in backfill density increases the residual earth pressure due to compaction.

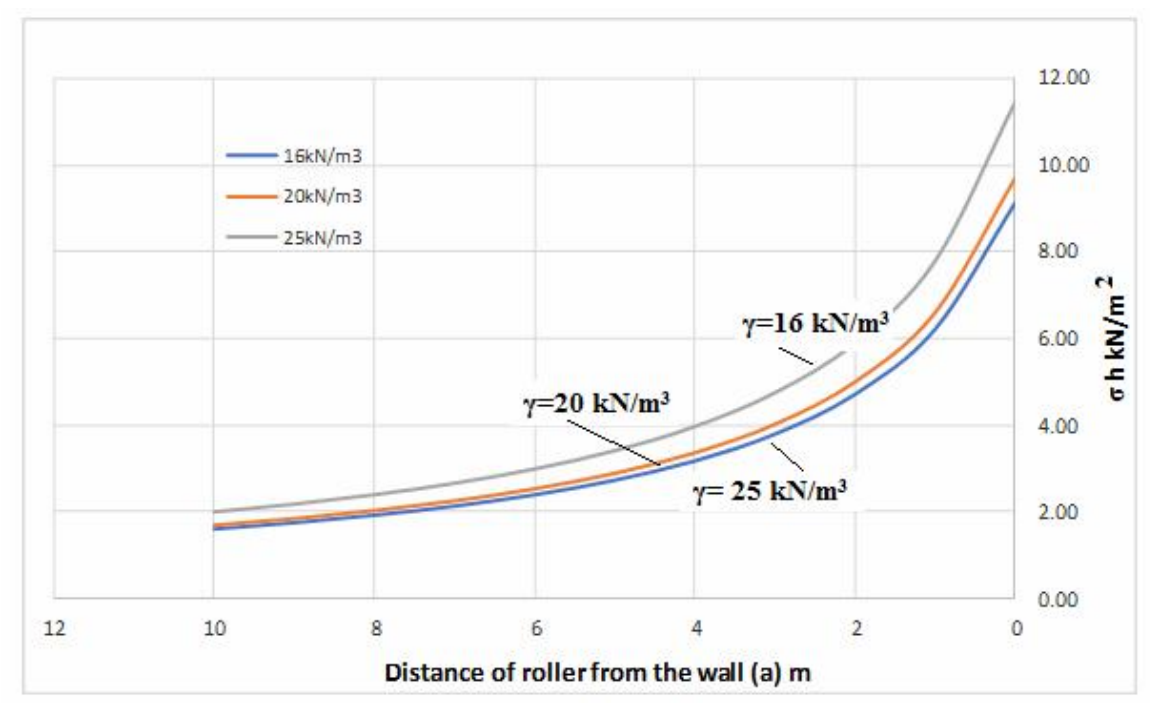

Figure (7) The relation between the residual lateral earth pressure due to compaction and backfill density

\section{4-2Effect of Roller Width on Compaction-Induced Earth Pressure}

Figure (8) shows the effect of roller width on compaction -induced earth pressure. The figure indicates that the lower the roller width, the lower the lateral pressure due to compaction, especially as the distances between the roller and the wall increase.

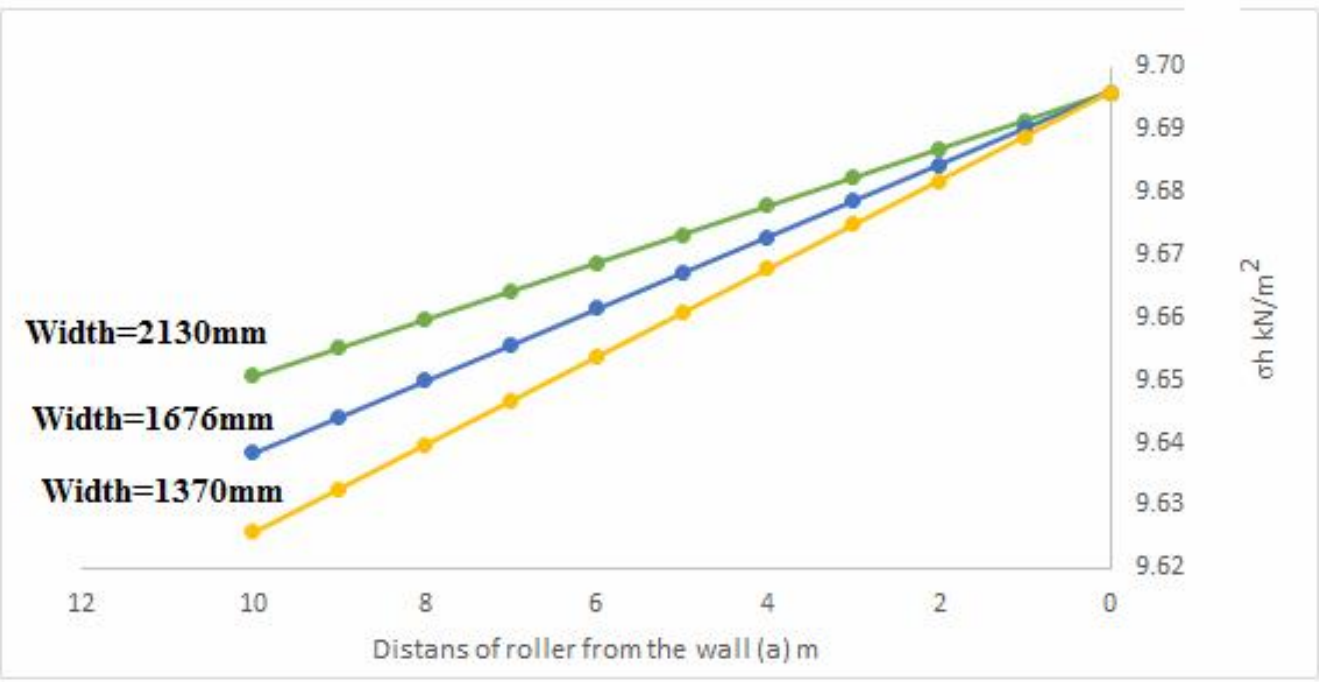

Figure (8) The effect of roller width on the residual lateral earth pressure due to compaction

\section{5- NUMERICAL MODEL}

The computer program Geo5 2018 was used during this analysis to calculate the earth pressure behind retaining wall due to compaction. GEO5 is a set of software, providing a solution for many geotechnical tasks based on the finite element method (see figure 9). The data that are provided to the program is as follows:

Wall height $=5 \mathrm{~m}$, angle of internal friction $(\phi)=30^{\circ}$, the wall friction $(\delta)=2 / 3 \phi$ (a common estimate), total force $=$ static weight $(\mathrm{Ps}) \mathrm{kN}+$ centrifugal force $(\mathrm{Pc}) \mathrm{kN}$, the distance between the wall and the roller, dimensions of roller, and unit weight $(\gamma)=18 \mathrm{kN} / \mathrm{m}^{3}$. 


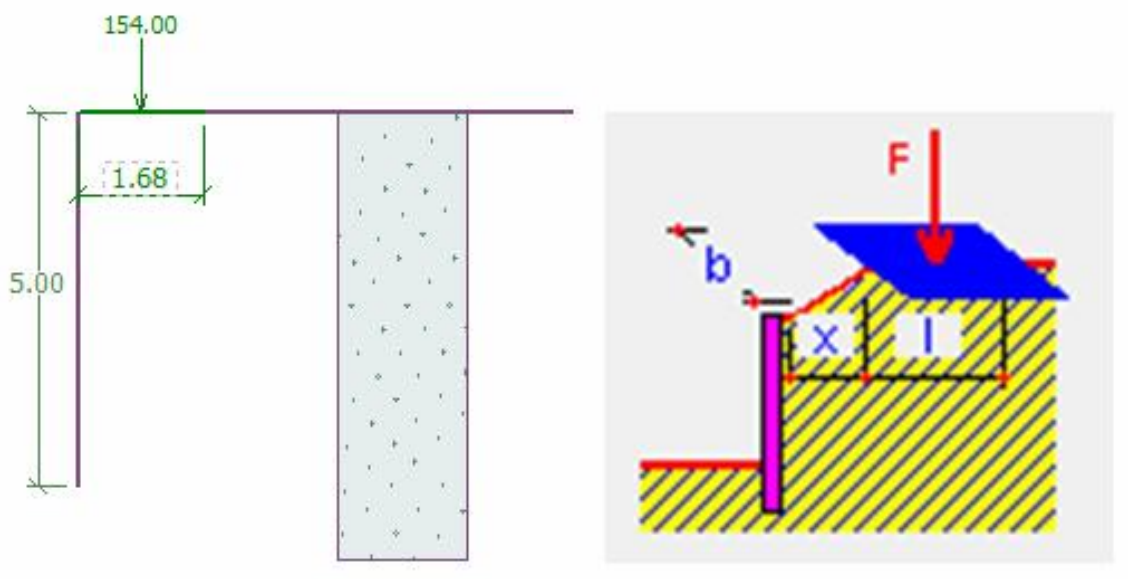

Figure (9) Finite element model

\section{5-1Numerical Model Results}

The results of the finite element model had been tabulated in table (3).

Table (3) The residual lateral pressure due to compaction by vibratory rollers according to the finite

\begin{tabular}{|c|c|c|c|c|c|c|}
\hline No. & Manufacturer & Model & $\begin{array}{l}\left(\mathbf{P}_{\mathbf{S}}\right) \\
\mathbf{k N}\end{array}$ & $\left(\mathbf{P}_{\mathrm{c}}\right) \mathbf{k N}$ & $\begin{array}{c}\text { Roller } \\
\text { width } \\
\text { (L)mm }\end{array}$ & $\begin{array}{r}\sigma_{\mathrm{hkN} / \mathrm{m}^{2}} \\
\mathbf{a}=\mathbf{0}\end{array}$ \\
\hline 1 & Dynapac & CA1300D & 13 & 89 & 1370 & 6.35 \\
\hline 2 & Dynapac & CA1400D & 20 & 144 & 1676 & 7.4 \\
\hline 3 & Dynapac & CA1500D & 21 & 133 & 1676 & 7.22 \\
\hline 4 & Dynapac & CA2500D & 26 & 250 & 2130 & 8.78 \\
\hline 5 & Dynapac & CA3600D & 36 & 280 & 2130 & 9.28 \\
\hline 6 & Dynapac & CA4000D & 41 & 270 & 2130 & 9.23 \\
\hline 7 & Dynapac & CA5000D & 50 & 330 & 2130 & 9.99 \\
\hline 8 & Dynapac & CA5500D & 56 & 360 & 2130 & 10.39 \\
\hline 9 & Dynapac & CA6000D & 60 & 360 & 2130 & 10.44 \\
\hline 10 & Dynapac & CA6500D & 65 & 360 & 2130 & 10.49 \\
\hline 11 & Dynapac & CA702D & 80 & 330 & 2130 & 10.33 \\
\hline 12 & $\begin{array}{l}\text { Ingersoll } \\
\text { Rand }\end{array}$ & $\begin{array}{l}\text { SD-70D PRO- } \\
\text { PAC }\end{array}$ & 63,65 & 135 & 1675 & 8 \\
\hline 13 & $\begin{array}{l}\text { Ingersoll } \\
\text { Rand }\end{array}$ & $\begin{array}{l}\text { SD-70F } \\
\text { TERRA } \\
\text { FIRMA } \\
\end{array}$ & 71.43 & 143 & 1676 & 8.28 \\
\hline 14 & $\begin{array}{l}\text { Ingersoll } \\
\text { Rand }\end{array}$ & SD-100D & 103.25 & 222.4 & 2134 & 9.32 \\
\hline 15 & $\begin{array}{l}\text { Ingersoll } \\
\text { Rand } \\
\end{array}$ & $\begin{array}{l}\text { SD-120D PRO- } \\
\text { PAC }\end{array}$ & 123.8 & 234 & 2135 & 9.76 \\
\hline 16 & $\begin{array}{l}\text { Ingersoll } \\
\text { Rand }\end{array}$ & $\begin{array}{l}\text { SD-150F PRO- } \\
\text { PAC }\end{array}$ & 148.95 & 314 & 2135 & 10.82 \\
\hline 17 & $\begin{array}{l}\text { Ingersoll } \\
\text { Rand } \\
\end{array}$ & $\begin{array}{l}\text { SD-180F PRO- } \\
\text { PAC }\end{array}$ & 180.4 & 360 & 2540 & 11.04 \\
\hline 18 & Bomag & BW 145 D-5 & 56 & 80 & 1426 & 7.13 \\
\hline 19 & Bomag & BW 177 D-5 & 78 & 112 & 1686 & 7.84 \\
\hline 20 & Bomag & BW 197 DH-5 & 84.4 & 112 & 1900 & 7.82 \\
\hline 21 & Bomag & BW 211 D-5 & 128.9 & 240 & 2130 & 9.8 \\
\hline 22 & Bomag & BW 211 D-40 & 130 & 236 & 2130 & 9.75 \\
\hline 23 & Bomag & BW 214 D-5 & 163 & 285 & 2130 & 10.11 \\
\hline
\end{tabular}


THE RESIDUAL LATERAL EARTH PRESSURE ON RETAINING WALL DUE TO VIBRATORY ROLLERS

\begin{tabular}{|c|l|c|c|c|c|l|}
\hline 24 & Bomag & BW 216 D-40 & 171 & 275 & 2130 & 10.62 \\
\hline 25 & Bomag & BW 218 D-40 & 191 & 275 & 2130 & 10.84 \\
\hline 26 & Bomag & BW 226 DH-5 & 267.1 & 328 & 2130 & 12.24 \\
\hline 27 & Caterpillar & CS34 & 44.45 & 66.8 & 1270 & 6.8 \\
\hline 28 & Caterpillar & CS44B & 72.1 & 133 & 1676 & 8.6 \\
\hline 29 & Caterpillar & CS54B & 105.55 & 234 & 2134 & 9.46 \\
\hline 30 & Caterpillar & CS64B & 120.55 & 234 & 2134 & 9.62 \\
\hline 31 & Caterpillar & CS78B & 187 & 332 & 2134 & 11.42 \\
\hline
\end{tabular}

\section{6- THE COMPARISON BETWEEN NUMERICAL MODEL RESULTS AND CANADIAN CODE OF PRACTICE METHOD}

Figure (10) shows the comparison between results from finite element model and method of Canadian code of practice

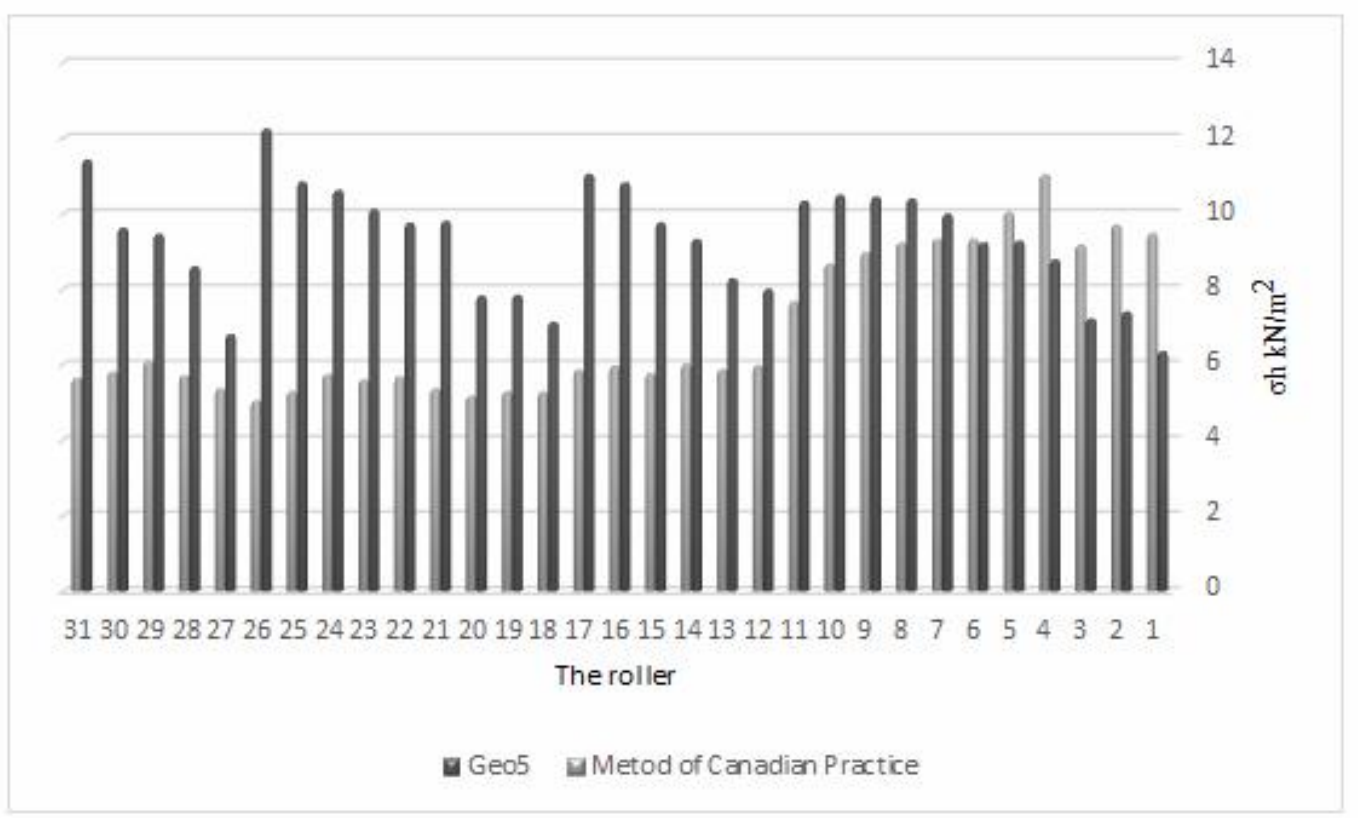

Figure (11) Comparison between results from Geo5 and Canadian code of practice

\section{7-CONCLUSION AND RECOMMENDATIONS}

The main conclusion and recommendations for this study can be concluded as follows:

1- The Canadian code of practice method gives a satisfactory result compared with finite element method especially in case of rollers with small static weight and high centrifugal

force such as Dynapac rollers.

2- When the roller work directly next to the wall the magnitude of the residual earth pressure will be maximum, then the pressure decreases to $10 \%$ of its maximum value at a distance equal $2 \mathrm{H}$ from the wall $(\mathrm{H}=$ the wall height). The pressure decreases until it reaches a value that can be neglected at a distance equal $4 \mathrm{H}$ from the wall.

3- It's recommended to decrease the lateral earth pressure due to compaction choose a compactor with high static weight and less centrifugal force. This condition is largely achieved in the equipment produced by the company Ingersoll Rand and Caterpillar.

4- A compaction by a small vibratory roller or a vibratory plate can be done till distances equal $0.6 \mathrm{H}$ from the wall or after the failure zone, then a big vibratory roller can be used if needed.

5- The effect of lateral earth pressure due to compaction must be taking into consideration especially for rigid wall founded on strong soil where there is not any movement of the wall which can fade the effect of compaction. 
6- The increase in backfill density increases the residual earth pressure due to compaction, so its recommended to avoid using a backfill which consists of sand and gravel behind the retaining wall where this type of backfill has a high density.

\section{REFERENCES}

[1] Craig, R. F., Soil Mechanics, Spon Press, $6^{\text {th }}$. Ed., 1997.

[2] Bowles, J.E. (1988), Foundation Analysis \&Design, 5th Edition, McGraw Hill, Sydney.

[3] Tsang-Jiang Chen and Yung-Show Fang, M.ASCE, (2008), "Earth Pressure due to Vibratory Compaction" , Journal of Geotechnical and Geo-environmental Engineering, ASCE,Vol. 134, No. 4, (437) .

[4] Broms, B. B. (1971). "Lateral earth pressures due to compaction of cohesionless soils." Proc. 4th Budapest Conference on Soil Mech. and Found. Engrg, 373-384.

[5] Duncan, J. M., and Seed, R. B. (1986). "Compaction-induced earth pressures under $\mathrm{K}_{\mathrm{o}}$ conditions." J-Geotech. Engrg. ASCE, 112(1).

[6] Peck, R. B., and Mesri, G. (1987). Discussion of "Soil-Structure Interaction Effects of Compaction-Induced Stresses and Deflections," J. Geot. Engrg., ASCE.

[7] G.F. Sowers, A.D. Robb, C.H. Mullis, and A.J. Glenn (1957). The residual lateral pressures produced by compacting soils. Proceedings of the 4th International Conference on Soil Mechanics and Foundation Engineering, vol. II: 243-247.

[8] M.S. Aggour and C.B. Brown (1974). The prediction of earth pressure on retaining walls due to compaction. Geotechnique, vol. 24, no. 4: 489-502.

[9] T.S. Ingold (1979). The effects of compaction on retaining walls. Geotechnique, vol. 29, no.3: 265283.

[10] Duncan, J.M., Williams G..W., Sehn A.L., and Seed, R.B. Estimation Earth Pressure Due to Compaction. Journal of Geotechnical Engineering, ASCE, 1992, 117, No. 12, pp. 1833-1847.

[11] H.Y.Fang, (1991), Foundation Engineering Hand book, $2^{\text {th }}$. Ed., Chapman \&Hall, New York.

[12] Canadian Foundation Engineering Manual, Canadian Geotechnical Society, 2006.

[13] I. CHMIELEWSKA, M. WYSOCKA, (2012), "Pressure on Retaining Walls from Compaction Effort" . Architecture civil engineering environment journal, the Silesian University of Technology, Vol. 5, No. 4, (55-60).

[14] Caterpillar (2017), "Caterpillar performance handbook", Caterpillar, Peoria, Illinois, U.S.A.

[15] Dynapac (2018), "Dynapac Instruction Manual Operating \& Maintenance", Karlskrona, Sweden.

[16] The website of Bomag worldwide, May 2018, https://www.bomag.com/world/en/products.htm 